\title{
Increased parasympathetic cardiac modulation in patients with acute exacerbation of COPD: how should we interpret it?
}

This article was published in the following Dove Press journal:

International Journal of COPD

28 July 2017

Number of times this article has been viewed

\author{
Erika Zavaglia Kabbach \\ Adriana Mazzuco \\ Audrey Borghi-Silva \\ Ramona Cabiddu \\ Aline Galvão Agnoleto \\ Jessica Fernanda Barbosa \\ Luiz Carlos Soares de \\ Carvalho Junior \\ Renata Gonçalves Mendes \\ Department of Physical Therapy, \\ Cardiopulmonary Physiotherapy \\ Laboratory, Federal University of Sao \\ Carlos, Sao Carlos, Sao Paulo, Brazil
}

Correspondence: Renata Gonçalves Mendes

Department of Physical Therapy,

Cardiopulmonary Physiotherapy

Laboratory, Federal University of Sao

Carlos, Rodovia Washington Luís, Km

235, Jardim Guanabara, I 3565-905 Sao

Carlos, Sao Paulo, Brazil

Tel +55 I6 33066704

$\mathrm{Fax}+55$ I6 336। 208।

Email renatamendes@ufscar
Background: Cardiac autonomic modulation (CAM) is impaired in patients with stable COPD. Exacerbation aggravates the patients' health status and functional capacity. While the clinical and functional effects of exacerbation are known, no studies investigated CAM during exacerbation and whether there is a relationship between CAM and functional capacity and dyspnea.

Methods: Thirty-two patients with moderate to severe COPD were enrolled into two groups: stable $\operatorname{COPD}(\mathrm{GSta}, \mathrm{n}=16)$ and acute exacerbation of COPD (GAE, $\mathrm{n}=16)$. The GAE patients were evaluated 24-48 hours after starting standard therapy for COPD exacerbation during hospitalization; the GSta patients were evaluated in an outpatient clinic and included in the study if no decompensation episodes had occurred during the previous month. The heart rate (HR) and R-wave peak detection intervals in ms (RRi) were registered using a heart rate monitor (Polar ${ }^{\mathbb{R}}$ system) at rest in seated position during 10 minutes. CAM was assessed by heart rate variability (HRV) linear and non-linear analysis. Functional capacity was evaluated by handgrip strength test, performed by Jamar ${ }^{\circledR}$ dynamometer, and dyspnea was scored using the modified scale of the Medical Research Council.

Results: GAE presented higher parasympathetic CAM values compared with GSta for square root of the mean squared differences of successive RRi (RMSSD; $17.8 \pm 5.6 \mathrm{~ms}$ vs $11.7 \pm 9.5 \mathrm{~ms}$ ); high frequency (HF; $111.3 \pm 74.9 \mathrm{~ms}^{2}$ vs $45.6 \pm 80.7 \mathrm{~ms}^{2}$ ) and standard deviation measuring the dispersion of points in the plot perpendicular to the line of identity (SD1; $12.7 \pm 3.9 \mathrm{~ms}$ vs $8.3 \pm 6.7 \mathrm{~ms}$ ) and higher CAM values for standard deviation of the mean of all of RRi (STD RRi; $19.3 \pm 6.5 \mathrm{~ms}$ vs $14.3 \pm 12.5 \mathrm{~ms})$; RRi tri $(5.2 \pm 1.7 \mathrm{~ms}$ vs $4.0 \pm 3.0 \mathrm{~ms})$; triangular interpolation of NN interval histogram (TINN; $88.7 \pm 26.9 \mathrm{~ms}$ vs $70.6 \pm 62.2 \mathrm{~ms}$ ); low frequency (LF; $203 \pm 210.7 \mathrm{~ms}^{2}$ vs $101.8 \pm 169.7 \mathrm{~ms}^{2}$ ) and standard deviation measuring the dispersion of points along the line of identity (SD2; $30.4 \pm 14.8 \mathrm{~ms}$ vs $16.2 \pm 12.54 \mathrm{~ms}$ ). Lower values were observed for the complexity indices: approximate entropy (ApEn; 0.9 \pm 0.07 vs $1.06 \pm 0.06$ ) and sample entropy (SampEn; $1.4 \pm 0.3$ vs $1.7 \pm 0.3$ ). Significant and moderate associations were observed between HF (nu) and handgrip strength $(r=-0.58 ; P=0.01)$ and between LF $\left(\mathrm{ms}^{2}\right)$ and subjective perception of dyspnea $(r=-0.53 ; P=0.03)$.

Conclusion: COPD exacerbated patients have higher parasympathetic CAM than stable patients. This should be interpreted with caution since vagal influence on the airways determines a narrowing and not a better clinical condition. Additionally, functional capacity was negatively associated with parasympathetic CAM in COPD exacerbation.

Keywords: pulmonary disease, hospitalization, autonomic nervous system, functional capacity

\section{Introduction}

COPD is a common preventable and treatable disease characterized by persistent airflow limitation that is usually progressive and associated with an enhanced chronic inflammatory response to noxious particles or gases in the airways and the lung. ${ }^{1} \mathrm{COPD}$ 
is a high cause of mortality and morbidity, affecting around 3 million individuals worldwide, ${ }^{2}$ which was the sixth cause of death in 1990 and will become the fourth leading cause of death in $2030 .^{3}$

Acute exacerbations of COPD (AECOPDs) are considered as the major cause of morbidity and mortality increase ${ }^{4}$ and one of the most common causes of hospitalization. ${ }^{5}$ AECOPD is considered as an acute event characterized by a worsening of the patient's respiratory symptoms beyond normal dayto-day variations and leads to a change in medication or to hospitalization. ${ }^{6}$

The occurrence of exacerbations and the increase in the frequency of these acute events can intensify the disease severity and have a considerable impact on patients' health status $^{7}$ and exercise capacity, ${ }^{8}$ a cumulative effect on lung function $^{9}$ and a detrimental and prolonged impact on other disease outcomes. ${ }^{10}$

It has been recognized that COPD is frequently related to an increased risk of developing cardiovascular diseases and cardiac autonomic system dysfunction. ${ }^{11}$ Patients with COPD present functional alterations in cardiac autonomic modulation (CAM) reflected by elevated resting heart rate (HR) and reduced heart rate variability (HRV). Higher respiratory work, hypoxemia, hypercapnia, increased intrathoracic pressure and systemic inflammation are some of the factors that have been shown to contribute to autonomic modulation impairment. ${ }^{12}$

Therefore, it should be emphasized that most studies and knowledge about CAM involve stable COPD patients and generally observe reduced HRV response to sympathetic and vagal stimuli. In terms of the association of HRV with functional aspects, Camillo et $\mathrm{al}^{13}$ identified that the lower level of daily life activity, quality of life and peripheral muscle strength are associated with HRV reduction.

The only study with patients in condition of disease decompensation was developed by Zamarrón et al. ${ }^{14}$ In this longitudinal study, the authors investigated CAM in monthly home visits when the exacerbation was identified; however, this design does not assure that the moment of evaluation corresponded to acute exacerbation, which can be considered an important bias; in addition, patients were not hospitalized, which is likely to aggravate the disease.

Considering that most COPD patients present at least one exacerbation per year and a substantial proportion (17\%) present three or more episodes per year, ${ }^{15}$ in addition to the worsening of clinical and functional injury for the hospitalization, the development of studies that investigate CAM and the possible relationships between the autonomic and functional variables in this clinical condition is fundamental to provide a better knowledge about these patients. Such information may be useful for a better understanding of the impact of exacerbation also from the viewpoint of the autonomic nervous system (ANS), which is responsible for the self-regulation and adaptability of the cardiac system. In addition, a better knowledge of this category of patients would allow health professionals to elaborate personalized and more adequate strategies of care.

In view of the above, the aim of this study was to evaluate CAM by HRV indices to standard in patients with COPD in a condition of exacerbation of the disease and to compare them with patients in a stable condition, besides investigating the possible relation of these autonomic variables with variables representative of functional capacity, health status, and subjective sensation of dyspnea. The hypothesis for this study is that CAM will be more impaired in patients with COPD in exacerbation condition compared with patients in stability and that worse autonomic function will be associated with worse clinical and functional profile.

\section{Methods}

\section{Subjects}

Thirty-two COPD patients were enrolled in this observational, cross-sectional clinical study. All patients presented with a clinical and spirometric diagnosis of COPD (forced expiratory volume in 1 second $\left[\mathrm{FEV}_{1}\right] /$ forced vital capacity, 0.7, and post-bronchodilator $\mathrm{FEV}_{1}, 80 \%$ predicted) in stages II, III and IV. ${ }^{1}$ COPD patients were evaluated in a specialized outpatient clinic of Hospital of São Paulo and in Hospital of São Carlos and were divided into the following groups: GSta $(n=16)$ and GAE $(n=16)$, composed of patients with a clinically stable COPD and acute exacerbation of COPD, respectively.

In GSta, no decompensation episodes occurred at least 1 month prior to study initiation and were optimally treated before initiation of the study. The GAE patients were evaluated at least 24 hours and within 48 hours after starting standard therapy (beta-2 agonist, anticholinergics, oral corticosteroids, short-acting bronchodilators, oxygen therapy and antibiotic treatment) for exacerbation of COPD on admission. Patients were breathing spontaneously and able to maintain dialog at the time of evaluation.

The non-inclusion criteria were peripheral vascular disease, the presence of neurological conditions that would preclude participation in the required protocol, other concomitant respiratory diseases, patients on mechanical ventilation, hemodynamic instability, presence of unstable angina or myocardial infarction history in the last 6 months. 


\section{Ethics aspects}

The study was approved by the research ethics committee of the Federal University of São Carlos (Brazil, reference number 2015/1220983) and by the coordinators of the Hospital of São Carlos and research ethics committee of the Hospital of São Paulo (Brazil, protocol $\left.n^{\circ} 473.529 / 2013\right)$. All the subjects and/or responsible people were informed about the study objectives and the experimental procedures and were ensured about the confidentiality of personal data. All subjects gave written informed consent before study initiation.

\section{Outcome measurements}

The primary outcome was the investigation of non-equality between HRV indices to standard in patients with COPD in the condition of exacerbation and disease stability. The secondary outcome was the investigation of the association between measures of functional capacity, subjective sensation of dyspnea and health status with autonomic cardiac modulation in patients with exacerbated COPD.

\section{Protocol}

All patients underwent a comprehensive evaluation: 1) clinical evaluation by a pneumologist and physiotherapist, followed by lung function tests (spirometry and maximal inspiratory and expiratory pressures). The lung function tests for the GAE were realized 30 days after the discharge. 2) Recording of HR and R-wave peak detection intervals (RRi) during rest for HRV analysis, functional capacity measures, dyspnea, and health status. The clinical variables HR, respiratory rate (RR), systolic and diastolic blood pressures and peripheral oxygen saturation $\left(\mathrm{SpO}_{2}\right)$ were collected at the beginning and end of the evaluations.

Subjects were instructed to abstain from caffeinated and alcoholic beverages and not to perform exercise on the day before data collection.

\section{Lung function}

For the staging of the disease and characterization of the sample, subjects underwent spirometry by forced vital capacity maneuvers with a spirometer (CPFS/S, Med Graphs and 1085 ELITE DTM; Medical Graphics Corporation, St Paul, MN, USA) according to the American Thoracic Society/ European Respiratory Society guidelines. ${ }^{16}$ Measurement of maximal inspiratory pressure (MIP) and maximal expiratory pressure (MEP) (manuvacuometric Ger Ar) was performed from the residual volume (RV) and total lung capacity (TLC), respectively. ${ }^{17}$

\section{Arterial blood gas}

For the characterization of the sample, arterial blood gas was measured at rest while breathing room air using a blood gas analyzer for the analysis of partial pressures of $\mathrm{O}_{2}$ and carbon dioxide $\left(\mathrm{CO}_{2}\right)$ (respectively, $\mathrm{PaO}_{2}$ and $\mathrm{PaCO}_{2}$, $\mathrm{mmHg}$ ), according to the European Respiratory Society recommendations. ${ }^{18}$

\section{Handgrip strength}

Handgrip strength has been previously described as an objective index of functional integrity of the upper limbs and as a parameter indicative of the general health of the adult; therefore, this test was performed as a measure of functional capacity. ${ }^{19}$ This test was performed by Jamar ${ }^{\circledR}$ dynamometer (Sammons Preston Rolyan, IL, USA) in kilogram-force (kgf). The patients remained seated with the elbow flexed at $90^{\circ}$ and forearm and wrist in a neutral position as standardization proposed by the American Society of Hand Therapists (ASHT). Three maximal voluntary contractions were requested with 30 seconds rest between them. The mean of the values obtained was used in the statistical analysis, and the measurements varied no $>5 \%$ between them. ${ }^{20}$

\section{Health status and dyspnea}

Health status was assessed by COPD Assessment Test (CAT), which comprises eight items, each with six levels. ${ }^{21}$ The dyspnea sensation reported by the patient was assessed by the Medical Research Council (MRC) scale, which uses a five-point scale. ${ }^{22}$

\section{Acquisition of RRi}

The RRi was registered using the Polar ${ }^{\circledR}$ system (Polar Electro, Kempele, Finland) at rest in the seated position during 10 minutes. All patients remained at rest for a period of 10 minutes before registration to ensure the stabilization of HR. An elastic belt (Polar T31 transmitter; Polar Electro) was attached to the chest of each volunteer at the level of the lower third of the sternum. The belt contains a stable case with HR electrodes, an electronic processing unit and an electromagnetic field transmitter. The HR signals were continuously transmitted to the Polar S810i receiver unit via an electromagnetic field. All data were transferred to a computer using Polar Pro-Trainer 5TM ${ }^{\circledR}$ software. ${ }^{23}$

\section{HRV analysis}

For HRV analysis, the RRi that differed by 20 beats/min from the mean of the analyzed period were excluded to minimize artifacts in the analysis. Only segments with $>90 \%$ pure sinus 
beats were included in the final analysis. A series containing sequential $256 \mathrm{RRi}^{24}$ was analyzed using Kubios $\mathrm{HRV}^{\circledR}$ version 2.1 software (Matlab, Kuopio, Finland).

HRV was analyzed by linear measurements in the time and frequency domains. The mean of RRi (mean RRi), the standard deviation of the mean of all RRi (STD RRi), the square root of the mean squared differences of successive RRi (RMSSD), the triangular index (RRi tri) and triangular interpolation of NN interval histogram (TINN) were obtained for time domain linear analysis. Low frequency (LF) and high frequency $(\mathrm{HF})$, both expressed in normalized units (nu) and milliseconds squared $\left(\mathrm{ms}^{2}\right)$, were calculated by spectral HRV analysis. ${ }^{25}$

Non-linear HRV analysis was performed to obtain SD1 (standard deviation measuring the dispersion of points in the plot perpendicular to the line of identity), SD2 (standard deviation measuring the dispersion of points along the line of identity), approximate entropy (ApEn) and sample entropy (SampEn) indices. SD1 is related to parasympathetic activity, while SD2 reflects total variability. ApEn detects changes in a time series and provides a non-negative number to the series; SampEn is very similar to the previous one but presents a computational difference. $^{26}$

\section{Statistical analysis}

The results are reported as mean \pm standard deviation or median (interquartile), and all statistical analyses were conducted at a $95 \%$ level of significance. According to variable distribution, the unpaired Student's $t$-test or Mann-Whitney rank sum test was performed to evaluate differences between HRV indices to standard in GAE and GSta. Pearson's or Spearman's correlation coefficient was used to test the association between HRV parameters and handgrip parameters, dyspnea and health status. The magnitude of correlations was determined considering the following classification scheme for $r$-values: $0.26-0.49$, low or weak; 0.50-0.69, moderate; $0.70-0.89$, strong or high and $0.90-1.0$, very high. ${ }^{27}$ To evaluate the quantitative distribution of the variables, the chi-square test was performed. To verify any possible impact of the gender imbalance in the study population on the results, an analysis of co-variance (ANCOVA) was performed. Statistical analysis was performed using SigmaPlot for Windows Version 11.0 (SyStat Software, Inc., San Jose, CA, USA).

\section{Results}

\section{Subject characteristics}

Thirty-two COPD patients (16 exacerbated COPD [70.31士 10.11] and 16 stable COPD [66.31 18.45$]$ ) were evaluated in this study. The subjects' characteristics are presented in Table 1. There were no differences in age, height or body mass index (BMI) between the groups. An ANCOVA was performed to verify any possible influence caused by gender imbalance in the groups. A $P>0.05$ was observed for all HRV indices, suggesting that gender did not influence the differences observed between the two groups. There was a significant difference for RR, with higher values for GAE. In relation to $\mathrm{SpO}_{2}$, there was no difference; however, significantly reduced $\mathrm{pO}_{2}$ values were observed for GSta, highlighting that in GAE, 11 patients were using oxygen supplementation $(1.75 \pm 1.48 \mathrm{~L} / \mathrm{min})$ and in GSta, none of them was. MIP and MEP $\left(\mathrm{cmH}_{2} \mathrm{O}\right)$ were significantly reduced in the GAE in comparison to the GSta $(P<0.001)$. In addition, both groups had patients classified in the Global Initiative for Chronic Obstructive Lung Disease (GOLD) stages II-IV; however, the exacerbated group had more patients (12) considered as severe $\left(\mathrm{FEV}_{1} 40.4 \% \pm 12.4 \%\right.$ and $53.9 \% \pm 19.7 \%$ of predicted, respectively).

\section{CAM}

The GAE patients presented significantly higher parasympathetic CAM values compared to GSta for the indices: RMSSD, HF and SD1. We also observed a significant difference between the parasympathetic components of the two groups (Figures 1 and 2). In addition, they presented higher values for the indices: STD RRi, RRi tri, TINN, LF and SD2. However, for the indices related to the evaluation of HR signal complexity (ApEn and SampEn), lower CAM values were observed for the exacerbated group compared to the stable group (Table 2).

\section{Relationship between HRV indices and functional capacity and subjective perception of dyspnea in the exacerbated patients}

Statistically significant associations between HRV indices and functional capacity indices were observed. HF (nu) showed moderate and negative correlation with handgrip strength $(r=-0.58 ; P=0.01)$ (Figure 3$)$. In addition, $\mathrm{LF}\left(\mathrm{ms}^{2}\right)$ showed a moderate and negative statistically significant association with subjective perception of dyspnea (questionnaire modified MRC $[\mathrm{mMRC}])(r=-0.53 ; P=0.03)$. No relationship was found between HRV variables and health status.

\section{Discussion}

In this study, we aimed to compare CAM assessed by linear and non-linear HRV indices to standard between patients 
Table I Baseline patients' characteristics

\begin{tabular}{|c|c|c|c|}
\hline Clinical data & GAE $(n=16)$ & GSta $(n=16)$ & $P$-value \\
\hline Age, years & $70.3 \pm 10.1$ & $66.3 \pm 8.4$ & 0.2 \\
\hline Gender, male/female (n) & $11 / 5$ & $16 / 0$ & 0.1 \\
\hline $\mathrm{BMI}, \mathrm{kg} / \mathrm{m}^{2}$ & $25.0 \pm 5.8$ & $24.7 \pm 4.2$ & 0.9 \\
\hline Exacerbation, $\mathrm{n} /$ year & $1.9 \pm 1.8$ & $1.0 \pm 0.9$ & 0.2 \\
\hline $\mathrm{mMRC}$ & $2.5(1.25-3)$ & $I(I-2)$ & 0.04 \\
\hline Smoking, never/ex/current & I (6.3)/I3 (8I.3)/2 (12.5) & $0 / 16(100) / 0$ & 0.03 \\
\hline Pack-years & $41.0 \pm 27.6$ & $48.0 \pm 26.9$ & 0.5 \\
\hline \multicolumn{4}{|l|}{ Clinical parameters } \\
\hline HR, bpm & $78.1 \pm 13.5$ & $81.2 \pm 9.9$ & 0.4 \\
\hline $\mathrm{RR}, \mathrm{rpm}$ & $21.6 \pm 2.2$ & $18.8 \pm 2.9$ & 0.006 \\
\hline $\mathrm{SBP}, \mathrm{mmHg}$ & $118.1 \pm 13.7$ & $123.2 \pm 17.2$ & 0.36 \\
\hline $\mathrm{DBP}, \mathrm{mmHg}$ & $75.6 \pm 8.1$ & $75.8 \pm 9.0$ & 1.0 \\
\hline $\mathrm{SpO}_{2}, \%$ & $93.5 \pm 3.2$ & $93.3 \pm 2.3$ & 0.08 \\
\hline \multicolumn{4}{|l|}{ Lung function } \\
\hline Forced vital capacity, \% predicted & $69.9 \pm 16.9$ & $92.6 \pm 21.1$ & 0.005 \\
\hline $\mathrm{FEV}_{1}, \%$ predicted & $40.4 \pm 12.4$ & $53.9 \pm 19.7$ & 0.04 \\
\hline $\mathrm{FEV}_{1} /$ forced vital capacity & $45.0 \pm 12.8$ & $56.5 \pm 14.0$ & 0.03 \\
\hline MIP $\left(\mathrm{cmH}_{2} \mathrm{O} / \%\right.$ predicted $)$ & $-30.7 \pm 15.6 / 28 \pm 18$ & $-92.4 \pm 32.3 / 92 \pm 30$ & $<0.001$ \\
\hline MEP $\left(\mathrm{cmH}_{2} \mathrm{O} / \%\right.$ predicted $)$ & $54.5 \pm 20.5 / 46 \pm 21$ & $125.8 \pm 30.4 / 112 \pm 34$ & $<0.001$ \\
\hline $\mathrm{PaO}_{2}, \mathrm{mmHg}$ & $91.3 \pm 35$ & $70.2 \pm 6.3$ & 0.01 \\
\hline $\mathrm{PaCO}_{2}, \mathrm{mmHg}$ & $40.8 \pm 7.2$ & $37.1 \pm 4.7$ & 0.1 \\
\hline \multicolumn{4}{|l|}{ Main comorbidities, n (\%) } \\
\hline Hypertension & II (68.8) & $9(56.3)$ & 0.1 \\
\hline Type 2 diabetes & $3(18.8)$ & $3(18.8)$ & 1.0 \\
\hline Stroke & $3(18.8)$ & 0 & 0.01 \\
\hline Alcoholism, ex/current & $2(12.5) / /(6.3)$ & $5(3 \mid .3) / 0$ & 0.1 \\
\hline \multicolumn{4}{|l|}{ Therapies, n (\%) } \\
\hline $\mathrm{laBa}$ & - & $\mathrm{I}(6.3)$ & \\
\hline $\mathrm{laBa}+\mathrm{ICs}$ & - & $5(3 \mid .3)$ & \\
\hline $\mathrm{laBa}+\mathrm{ICs}+\mathrm{laMa}$ & - & $9(56.3)$ & \\
\hline $\mathrm{laBa}+\mathrm{laMa}$ & - & I (6.3) & \\
\hline $\mathrm{saBa}+\mathrm{ICs}$ & $4(25)$ & - & \\
\hline $\mathrm{saBa}+\mathrm{ICs}+\mathrm{saMa}$ & $10(62.5)$ & - & \\
\hline $\mathrm{saBa}+\mathrm{saMa}$ & $2(12.5)$ & - & \\
\hline
\end{tabular}

Note: Data are presented as mean \pm SD or median (interquartile).

Abbreviations: BMI, body mass index; mMRC, modified Medical Research Council; HR, heart rate; RR, respiratory rate; SBP, systolic brachial pressure; DBP, diastolic brachial pressure; $\mathrm{FEV}_{1}$, forced expiratory volume in I second; MIP, maximal inspiratory pressure; MEP, maximal expiratory pressure; laBa, long-acting beta-2 agonist; ICs, inhaled corticosteroids; laMa, long-acting anticholinergics; saBa, short-acting beta-2 agonist; saMa, short-acting anticholinergics; SD, standard deviation; GAE, acute exacerbation COPD group; GSta, stable COPD group.

with COPD in stable condition and those in a condition of exacerbation of the disease. Additionally, we studied the relationship between HRV indices to standard with measures of functional capacity, dyspnea, and health status.

The main findings of the study were that the patients in the condition of exacerbation had higher values of parasympathetic and global HRV and lower values of complexity of the HR signal compared to the patients in stable condition. In addition, we observed that the functional capacity and the subjective perception of dyspnea are associated with cardiac autonomic indices to standard. The HF index (representative of the parasympathetic modulation) was negatively associated with the handgrip strength. The LF index (predominantly sympathetic) was negatively associated with the subjective perception of dyspnea.

To our knowledge, this is the first study to explore CAM in patients in clinical condition of exacerbation, evaluated within 24-48 hours after hospitalization, and to investigate the interaction between CAM, functional capacity and subjective perception of dyspnea in the exacerbation of COPD. The ANS is responsible for the regulation of several physiological processes, and its integrity and functionality allow the maintenance of the condition of stability even in the presence of stressors, ${ }^{12}$ which justifies the importance of this study.

In this context, CAM evaluation can be performed via HRV analysis. Thus, HRV is an important tool for obtaining 

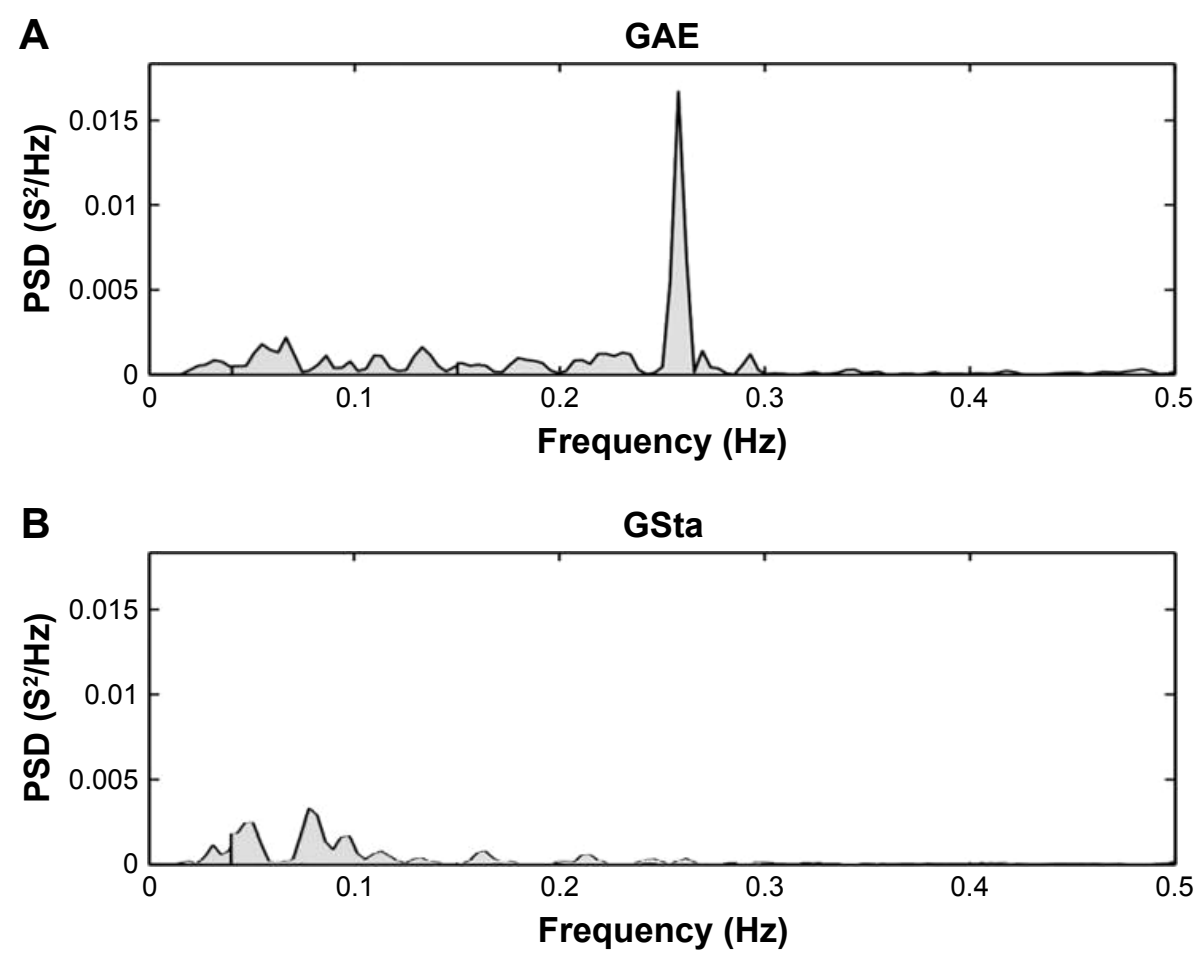

Figure I PSD for (A) a patient from the exacerbated group and (B) a patient from the stable group.

Abbreviations: PSD, power spectral density; GAE, acute exacerbation COPD group; GSta, stable COPD group.

information about cardiac regulation, and several studies associate abnormal HRV responses with a higher risk of morbidity, cardiac events and mortality. ${ }^{28}$ Thus, it is well accepted that adequate HRV reflects the healthy function, self-regulation and adaptability of the cardiac system.

HRV has demonstrated great clinical importance in several sectors and conditions. We can cite a study that demonstrated that HRV indices are useful as a prognostic tool in preoperative cardiac surgery ${ }^{29}$ as well as early markers of ventricular tachycardia. ${ }^{30}$ Therefore, studies that demonstrate and characterize HRV alterations may represent a starting point for future research involving intervention strategies and prognostic research. It is important to emphasize that the important relationship between pulmonary disease and cardiovascular impairment also adds to the research base for this research purpose.

A recent systematic review has shown a strong level of evidence to support the impairment of autonomic function
A

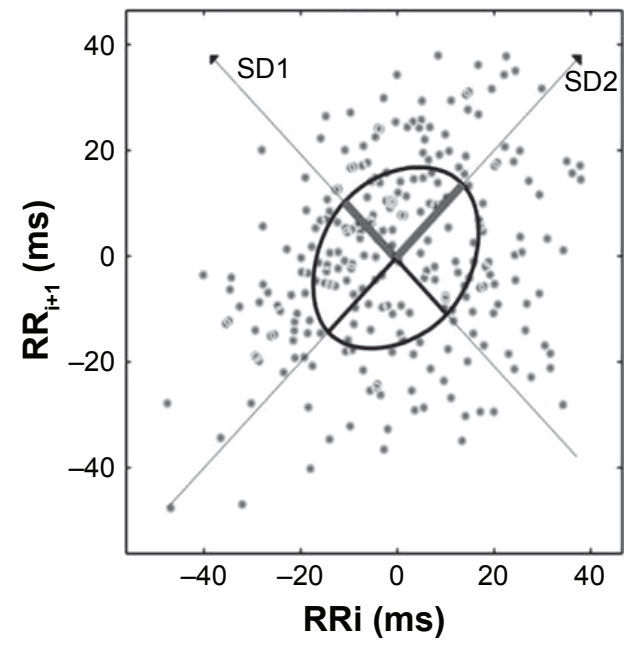

B

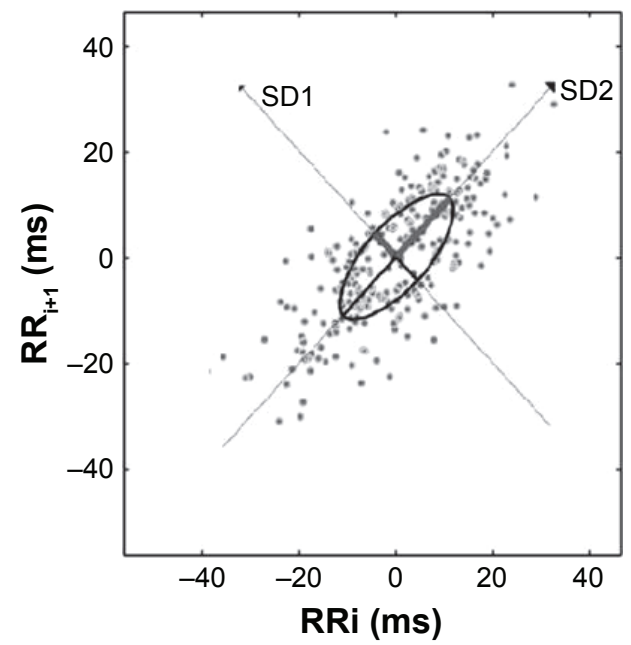

Figure 2 Poincare plots for (A) a patient from the exacerbated group and (B) a patient from the stable group.

Abbreviations: RRi, R-wave peak detection intervals; SDI, standard deviation measuring the dispersion of points in the plot perpendicular to the line of identity; SD2, standard deviation measuring the dispersion of points along the line of identity; GAE, acute exacerbation COPD group; GSta, stable COPD group. 
Table 2 HRV values

\begin{tabular}{|c|c|c|c|}
\hline HRV index & GAE & GSta & $P$-value \\
\hline \multicolumn{4}{|l|}{ Time domain } \\
\hline Mean RRi, ms & $721.6 \pm 106.9$ & $736.8 \pm 133.5$ & 0.72 \\
\hline STD RRi, ms & $19.3 \pm 6.5$ & $14.3 \pm 12.5$ & 0.007 \\
\hline RMSSD, ms & $17.8 \pm 5.6$ & $11.7 \pm 9.5$ & 0.008 \\
\hline RRi tri & $5.2 \pm 1.7$ & $4.0 \pm 3.0$ & 0.01 \\
\hline TINN, ms & $88.7 \pm 26.9$ & $70.6 \pm 62.2$ & 0.01 \\
\hline \multicolumn{4}{|c|}{ Frequency domain } \\
\hline$L F, \mathrm{~ms}^{2}$ & $203.0 \pm 210.7$ & $101.8 \pm 169.7$ & 0.01 \\
\hline $\mathrm{HF}, \mathrm{ms}^{2}$ & $111.3 \pm 74.9$ & $45.6 \pm 80.7$ & 0.002 \\
\hline $\mathrm{LF} / \mathrm{HF}$ & $2.5 \pm 2.1$ & $2.3 \pm 2.0$ & 0.6 \\
\hline \multicolumn{4}{|c|}{ Non-linear analysis } \\
\hline SDI & $12.7 \pm 3.9$ & $8.3 \pm 6.7$ & 0.007 \\
\hline SD2 & $30.4 \pm 14.8$ & $16.2 \pm 12.5$ & $<0.001$ \\
\hline ApEn & $0.9 \pm 0.07$ & $1.0 \pm 0.06$ & 0.002 \\
\hline SampEn & $1.4 \pm 0.32$ & $1.7 \pm 0.3$ & 0.007 \\
\hline
\end{tabular}

Abbreviations: HRV, heart rate variability; RRi, R-wave peak detection intervals; STD RRi, standard deviation of RRi; RMSSD, root mean square of successive differences; RRi tri, triangular index; TINN, triangular interpolation of RRi; LF, low frequency; HF, high frequency; SDI, beat-to-beat variability; SD2, standard deviation of long-term variability; ApEn, approximate entropy; SampEn, sample entropy; GAE, acute exacerbation COPD group; GSta, stable COPD group.

parameters in subjects with COPD. ${ }^{31}$ Using HRV analysis, Reis et $\mathrm{al}^{32}$ demonstrated a reduction in CAM in patients with moderate COPD in a condition of clinical stability compared to a control group. Against these findings, Dias de Carvalho et $\mathrm{al}^{33}$ observed that COPD patients present an SD1 reduction, which indicates a reduced vagal modulation, and reduction of $\mathrm{SD} 2$, TINN and RRi tri indices, related to overall reduction in autonomic modulation.

Most of these studies reported significantly lower HRV in subjects with COPD; however, they were performed in conditions of disease stability. In contrast with these findings, in this study, which involves patients in condition of nonstability, we found that GAE patients presented higher values

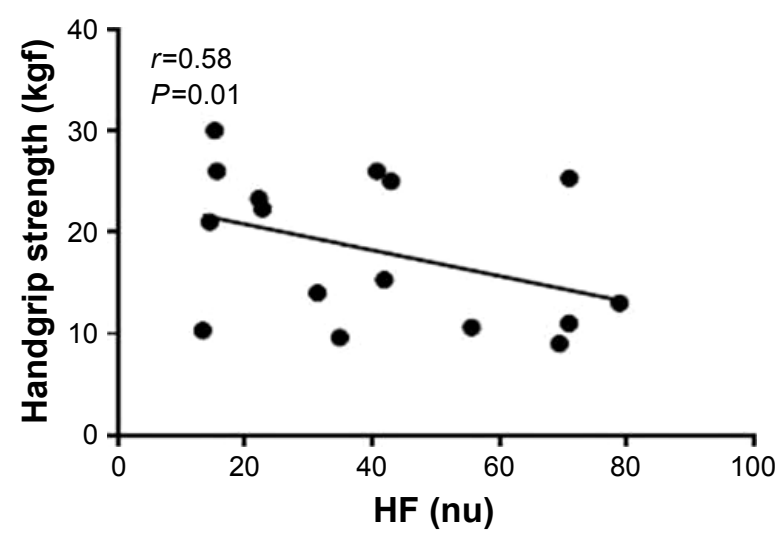

Figure 3 Correlations between HRV indices to standard and functional capacity Notes: Data are presented as the correlation coefficient $(r)$ and $P<0.05$. HF (nu): high frequency expressed in normalized units; handgrip strength expressed in kilogram-force (kgf).

Abbreviations: HRV, heart rate variability; HF, high frequency. of parasympathetic and overall HRV indices represented by RMSSD, HF, SD1, STD RRi, RRi tri, TINN and SD2 compared to stable patients.

In a study involving exacerbated patients, the authors also found higher LF, HF and total HRV power. ${ }^{14}$ However, unlike in this study, which involved only patients evaluated within 24-48 hours after exacerbation, the authors did not standardize the evaluation time and performed the evaluation in a home care program. Additionally, the analysis of non-linear HRV indices was not performed.

Therefore, in the exacerbation condition of the disease, our findings suggest that there is a parasympathetic modulation prevalence and an HRV increase in COPD patients evaluated within $24-48$ hours after starting standard therapy for this condition. Some possible explanations may justify this finding. First, we speculate that due to the presence of bronchoconstriction, narrowing the airways and aggravating airflow obstruction, the vagal activity in the airways is increased and could translate into an alteration of the HRV indices representative of such modulation.

Previously, Volterrani et $\mathrm{al}^{34}$ found that stable COPD patients had an increase in the HF power caused by an increase in vagal activity that was explained in part by $\mathrm{FEV}_{1}$ reduction and the increase in bronchoconstriction observed in these patients. In our study, we observed a significantly lower $\mathrm{FEV}_{1}$ for the exacerbated group and also found higher HF values $\left(\mathrm{ms}^{2}\right)$ for GAE compared to GSta. Such findings lead us to question whether in the study by Volterrani et al the patients were indeed in the condition of stability. Reinforcing these results, we could verify a worsening in the respiratory function, verified by a higher subjective perception of dyspnea. This influence of the autonomic modulation on the airway, which regulates the smooth muscle, was also related to the symptoms and clinical characteristics of asthma and COPD. ${ }^{35,36}$

The increased HF variability supports the view that, in humans, airway tone is mainly vagally controlled. ${ }^{37}$ Hashimoto et $\mathrm{al}^{38}$ also reported a higher vagal tone and correspondingly low sympathetic tone measured as HF and LF variance in exacerbated asthmatics.

It is important to note that the widespread pattern attributed to worst clinical outcomes, diseases and complications include increased sympathetic modulation and withdrawal of parasympathetic modulation, while higher $\mathrm{HRV}$ is associated with a good prognosis in both healthy and disease states, as previously evidenced. ${ }^{39}$ Thus, it is possible to emphasize that caution is required in interpreting the results about CAM in patients with COPD during the exacerbation condition. In this situation, higher vagal modulation evaluated by 
HRV does not correspond to a better clinical condition. It is also important to note that systemic inflammatory response is common in COPD patients and may be even more pronounced during an acute exacerbation. The pro-inflammatory cytokines tumor necrosis factor (TNF) and interleukin (IL)-1 have already been demonstrated to be able to down-regulate parasympathetic and sympathetic function. However, in this study, even though no information was provided about it, this inflammatory factor does not appear to be the main modulator of HRV during exacerbation.

Other possible factors influencing autonomic function in patients with COPD are the respiratory parameters. ${ }^{40}$ The respiratory pattern has been related to the autonomic modulation, and the parasympathetic modulation has been shown to depend on both lung hyperinflation and RR. In these patients, chronic hyperinflation reduces the response to stimuli related to the Hering Breuer reflex due to permanent activation of the fibers of the pulmonary stretching receptors, which may result in maintenance of vagal activity ${ }^{12}$ and explain in part our findings. However, it is worth noting that in the condition of stability, even in the presence of hyperinflation, this aspect does not appear to be the main modulator of CAM since the vagal indices to standard are reduced and the sympathetic activation is increased in this population.

Regarding RR, GAE patients presented significantly higher values than the GSta (21.6 \pm 2.2 and $18.8 \pm 2.9$ breaths/minute, respectively). In a previous study, both $\mathrm{HF}$ and LF were negatively correlated with RR ( $r=-0.76$ and -0.70 , respectively) in subjects with COPD. ${ }^{41}$ In our study, the results were contrasting since we observed higher values of RR, HF and LF for GAE. Previous authors suggested that patients with COPD are less able to respond to sympathetic and parasympathetic stimuli, compared to normal subjects at rest. They observed that the COPD patients' control system is working at saturation level, so they may not be able to present the same range of variation of normal people and even opposite stimuli cannot modify their autonomic behavior. ${ }^{34}$

In agreement, another previous study did not observe any RR and tidal volume influence on HRV. The small effect of volume on respiratory HR variations was also shown (a 50\% increase in tidal volume results in only a $15 \%$ increase in sinus arrhythmia). ${ }^{42}$ Others authors demonstrated that the breathing parameters did not alter average RRi and that variations of respiration distribute autonomic outflow within the respiratory cycle but do not alter net levels of autonomic activity. Thus, vagal activity during the various phases of the respiratory cycle varied considerably, whereas the overall tonic level remained constant. ${ }^{40}$

Evaluating other possible factors of influence, previous studies already investigated the relationship between arterial blood gas parameters and autonomic function parameters in patients with COPD. ${ }^{43}$ Acute hypoxemia increases sympathetic nerve activity by stimulation of arterial chemoreceptors in healthy humans. ${ }^{44}$ On the other hand, in chronic hypoxemic patients, a negative association between $\mathrm{HF}$ and $\mathrm{PaO}_{2}$, attributed to long-period arterial oxygen reduction damages, was identified, which would result in increased parasympathetic modulation in stable COPD. ${ }^{43}$ In this study, for GAE patients, higher $\mathrm{PaO}_{2}$ values were obtained at the cost of oxygen supplementation during hospitalization, which does not rule out the damage to the chemoreceptor afferent fibers before the exacerbation. Although this finding cannot be confirmed, we have attributed our findings to the possible influence of this factor.

It is important to highlight that in our study, the majority of the GAE patients were in use of short-acting beta-2 agonists. They are responsible for relaxing the smooth muscle, acting on cholinergic receptors and selectively blocking parasympathetic activity. ${ }^{45}$ In this sense, our findings of higher parasympathetic modulation demonstrate that the autonomic vagal activity probably still remained predominant on the airways.

Regarding the linear indices to standard that represent overall HRV, we observed higher values for the exacerbated group. As already mentioned earlier, there is evidence that the COPD patients present lower values for overall HRV in stable condition; however, our findings were opposite between exacerbation and stability condition. It is speculated that these higher values for the overall indices are justified by the vagal overactivity modulation evidenced by the other indices, besides a higher LF component.

There is an increasing interest in evaluating complexity of the short-term cardiovascular control via heart period variability analysis. ${ }^{46}$ Non-linear analyses are related to the fact that nature is random and not periodic, and in the dynamics of HRV, a healthy heart beat is irregular. Thus, in this study, we can suggest that the lower complexity observed for the exacerbated group in comparison to the stable group is related to worse cardiovascular dynamics since it is associated with the interaction of all the mechanisms that regulate the ANS. Cheng et $\mathrm{al}^{47}$ also observed that patients with COPD present reduced ANS complexity compared with healthy subjects but only evaluated stable patients. 
Exploring another aspect of this study, we know that one of the main impacts of COPD is the progressive loss of physical performance, which increases the level of disability of these patients. ${ }^{48}$ In this context of functional evaluation, the handgrip strength is a validated measure that reflects the patient's overall strength and consequent functional capacity. Therefore, an understanding of the relationship between HRV and function during exacerbation may help us find out if $\mathrm{HRV}$ is associated with the various aspects of this complex and multifactorial disease and subsequently allow the proposition of intervention strategies that may influence the outcomes involved.

Thus, this study was able to identify that functional capacity is related to the cardiovascular system in the exacerbation of the disease. More specifically, the parasympathetic modulation overactivity in the exacerbation condition is associated with a lower handgrip strength, which may indicate that high parasympathetic modulation translates into worse clinical condition reflecting the worse performance in this test. Another interesting finding of this study was the negative relation between the subjective perception of dyspnea in the mMRC scale and the LF, which can be interpreted as lower dyspnea associated with higher sympathetic predominance. A previous study evaluated the influence of dyspnea on autonomic function in individuals with COPD and showed an association between dyspnea and RMSSD $(r=0.48) .{ }^{49}$ Thus, we can infer that the dyspnea sensation can be reflected in the autonomic cardiac function.

Some limitations of our study should be considered. Assessments of pulmonary hyperinflation and airway narrowing have not been performed, which does not allow our findings to be attributed to a specific cause. However, we could confirm that although both groups are affected by the same disease, they present a considerable difference in the cardiovascular autonomic profile. The clinical implication of these findings needs to be investigated.

\section{Conclusion}

We conclude, based on the findings of this study, that patients with exacerbated COPD have higher parasympathetic autonomic cardiac modulation compared to stable patients. This finding can be attributed, among other factors, to the influence of vagal activity on the respiratory system, which results in narrowing of the airways and consequent worse clinical status. Reinforcing these findings, it was possible to verify that functional capacity is associated with CAM.

\section{Disclosure}

The authors report no conflicts of interest in this work.

\section{References}

1. Global Initiative for Chronic Obstructive Lung Disease. Global Strategy for the Diagnosis, Management, and Prevention of Chronic Obstructive Pulmonary Disease Updated 2016. A collaborative project of the National Heart, Lung and Blood Institute, Nationals Institutes of Health, and the World Health Organization; 2016

2. Rake KF, Hurd AS, Anzueto A, Barnes PJ, Peter J, Buist AS. Global strategy for diagnosis, management, and prevention of chronic obstrutive pulmonar disease: GOLD Executive Summary. Am J Respir Crit Care Med. 2007;176(6):532-555.

3. Mathers CD, Loncar D. Projections of global mortality and burden of disease from 2002 to 2030. PLoS Med. 2006;3(11):e442.

4. Wedzicha JA, Donaldson GC. Exacerbations of chronic obstructive pulmonary disease. Respir Care. 2003;48(12):1204-1213.

5. Soler-Cataluna JJ, Martınez-Garcıa MA, Roman Sanchez P, Salcedo E, Navarro M, Orchando R. Severe acute exacerbations and mortality in patients with chronic obstructive pulmonary disease. Thorax. 2005;60(11):925-931.

6. Pavord ID, Jones PW, Burgel PR, Rabe KF. Exacerbations of COPD Int J COPD. 2016;11:21-30.

7. Spencer S, Jones PW; GLOBE Study Group. Time course of recovery of health status following an infective exacerbation of chronic bronchitis. Thorax. 2003;58(7):589-593.

8. Cote CG, Dordelly LJ, Celli BR. Impact of COPD exacerbations on patient-centered outcomes. Chest. 2007;131(3):696-704.

9. Celli BR, Thomas NE, Anderson JA, et al. Effect of pharmacotherapy on rate of decline of lung function in chronic obstructive pulmonary disease: results from the TORCH study. Am J Respir Crit Care Med. 2008;178(4): 332-338.

10. Jones PW, Lamarca R, Chuecos F, et al. Characterisation and impact of reported and unreported exacerbations: results from ATTAIN. Eur Respir J. 2014;44(5):1156-1165.

11. Stewart AG, Waterhouse JC, Howard P. Cardiovascular autonomic nerve function in patients with hypoxaemic chronic obstructive pulmonary disease. Eur Respir J. 1991;4(10):1207-1214.

12. Gestel AJR, Steier J. Autonomic dysfunction in patients with chronic obstructive pulmonary disease (COPD). J Thorac Dis. 2010;2(4):215-222.

13. Camillo CA, Pitta F, Possani HV, et al. Heart rate variability and characterisitics disease in patients with COPD. Lung. 2008;186(6):393-401.

14. Zamarrón C, Lado TT, Morete E, Vila XA, Lamas PF. Heart rate variability in patients with severe chronic obstructive pulmonar disease in a home care program. Technol Health Care. 2014;22(1):91-98.

15. Vestbo J. Clinical assessment, staging, and epidemiology of chronic obstructive pulmonary disease exacerbations. Proc Am Thorac Soc. 2006; 3(3):252-256.

16. Miller MR, Hankinson J, Brusasco V, et al. ATS/ERS Task Force. Standardisation of spirometry. Eur Respir J. 2005;26(2):319-338.

17. Neder JA, Andreoni S, Lerario MC, Nery LE. Reference values for lung function tests: II. Maximal respiratory pressures and voluntary ventilation. Braz J Med Biol Res. 1999;32(6):719-727.

18. Quanjer PH, Tammeling GJ, Cotes JE, Pedersen OF, Peslin R, Yernault JC. Lung volumes and forced ventilatory flows. Report Working Party Standardization of Lung Function Tests, European Community for Steel and Coal. Official Statement of the European Respiratory Society. Eur Respir J Suppl. 1993;16:5-40.

19. Castro RNS. Correlação entre a força de preensão manual e a força da musculatura respiratória em mulheres asmáticas e não asmáticas; 2009. $66 \mathrm{f}$

20. Abdalla IM, Brandão MC. Forças de preensão palmar e da pinça digital. Sociedade Brasileira de Terapeutas da Mão. Recomendações para avaliação do membro superior. SBTM; São Paulo: 2005:38-41. 
21. Jones PW, Harding G, Berry P, Wiklund I, Chen WH, Kline Leidy N. Development and first validation of the COPD Assessment Test. Eur Respir J. 2009;34(3):648-654.

22. Kovelis D, Segretti NO, Probst VS, Lareau SC, Brunetto AF, Pitta F. Validation of the Modified Pulmonary Functional Status and Dyspnea Questionnaire and the Medical Research Council scale for use in Brazilian patients with chronic obstructive pulmonary disease. $J$ Bras Pneumol. 2008;34(12):1008-1018.

23. Radespiel-Troger M, Rauh R, Mahlke C, Gottschalk T, Muck-Weymann M. Agreement of two different methods for measurement of heart rate variability. Clin Auton Res. 2003;13(2):99-102.

24. Camm A, Malik M, Bigger J, et al. Task Force of European Society of Cardiology and the North American Society of Pacing Electrophysiology. Heart rate variability: standards of measurement, physiological interpretation, and clinical use. Circulation. 1996;93(5):1043-1065.

25. Freeman JV, Dewey FE, Hadley DM, Myers J, Froelicher VF. Autonomic nervous system interaction with the cardiovascular system during exercise. Prog Cardiovasc Dis. 2006;48(5):342-362.

26. Ferreira MT. Characterization of heart rate variability (HRV) chaotic behavior in healthy young people. TEMA Tend Mat Appl Comput. 2010; 11:141-151.

27. Munro BH. Statistical Methods for Health Care Research. 4th ed. Philadelphia, PA: JB Lippincott; 2000.

28. Bilmann GE, Schwartz PJ, Stone HL. Baro-receptor reflex control of heart rate: a predictor of sudden cardiac death. Circulation. 1982;66(4): $874-880$.

29. Godoy MF, Takakura IT, Correa PR. The relevance of nonlinear dynamic analysis (Chaos Theory) to predict morbidity and mortality in patients undergoing surgical myocardial revascularization. Arq Cienc Saúde. 2005;12(4):167-171.

30. Meyerfeldt U, Wessel N, Schutt H, et al. Heart rate variability before the onset of ventricular tachycardia: differences between slow and fast arrhythmias. Int J Cardiol. 2002;84(23):141-151.

31. Mohammed J, Meeus M, Derom E, Silva H, Calders P. Evidence for autonomic function and its influencing factors in subjects with COPD: a systematic review. Respir Care. 2015;60(12):1841-1851.

32. Reis MS, Arena R, Deus AP, Simões RP, Catai AM, Borghi-Silva A. Deep breathing heart rate variability is associated with respiratory muscle weakness in patients with chronic obstructive pulmonary disease. Clinics. 2010;65(4):369-375.

33. Dias de Carvalho C, Pastre MR, Rossi C, Abreu LC, Valenti VE, VanderleiLCM. Geometric index of heart rate variability in chronic obstructive pulmonary disease. Rev Port Pneumol. 2011;17(6):260-265.

34. Volterrani M, Scalvini S, Mazzuero G, et al. Decreased heart rate variability in patients with chronic obstructive pulmonary disease. Chest. 1994; 106(5):1432-1437.

35. Gross NJ, Co E, Skorodin MS. Cholinergic bronchomotor tone in COPD. Estimates of its amount in comparison with that in normal subjects. Chest. 1989;96(5):984-987.
36. Proskocil BJ, Fryer AD. Beta2-agonist and anticholinergic drugs in the treatment of lung disease. Proc Am Thorac Soc. 2005;2(4):305-310. Discussion 311-2.

37. Garrard CS, Seidler A, McKibben A, McAIpine LE, Grdon D. Spectral analysis of heart rate variability in bronchial asthma. Clin Auton Res. 1992;2(2):105-111.

38. Hashimoto A, Maeda H, Yokoyama M. Augmentation of parasympathetic nerve function in patients with extrinsic bronchial asthma-evaluation by coefficiency of variance of R-R interval with modified long-term ECG monitoring system. Kobe J Med Sci. 1996;42(6):347-359.

39. Zulfiqar U, Jurivich DA, Gao W, Singer DH. Relation of high heart rate variability to healthy longevity. Am J Cardiol. 2010;105(8): 1181-1185.

40. Brown TE, Beightol LA, Koh J, Eckberg DL. Important influence of respiration on human R-R interval power spectra is largely ignored. J Appl Physiol (1985). 1993;75(5):2310-2317.

41. Chang ET, Silberstein D, Rambod M, Porszasz J, Casaburi R. Heart rate variability during constant work rate exercise at and above the critical power in patients with severe chronic obstructive pulmonary disease. Tzu Chi Med J. 2011;23(2):42-45.

42. Edstrom H, Choslovky S, Cherniack R. The effect on lung volume on the ventilatory response to $\mathrm{CO} 2$ during resistive loading in normal subjects. Am Rev Respir Dis. 1976;114(4):761-766.

43. Chen WL, Chen GY, Kuo CD. Hypoxemia and autonomic nervous dysfunction in patients with chronic obstructive pulmonary disease. Respir Med. 2006;100(9):1547-1553.

44. Leuenberger U, Gleeson K, Wroblewski K, et al. Norepinephrine clearance is increased during acute hypoxemia in humans. Am J Physiol. 1991;261(5 pt 2):1659-1664.

45. Paolo M. Pharmacological treatment of chronic obstructive pulmonary disease. Int J COPD. 2006;1(4):409-423.

46. Bigger JT Jr, Steinman RC, Rolnitzky LM, Fleiss JL, Albrecht P, Cohen RJ. Power law behavior of RR-interval variability in healthy middle-aged persons patients with recent acute myocardial infarction and patients with heart transplants. Circulation. 1996;93(12):2142-2151.

47. Cheng ST, Wu YK, Yang MC, Huang CY, Chu WH, Lan CC. Pulmonary rehabilitation improves heart rate variability at peak exercise, exercise capacity and healthrelated quality of life in chronic obstructive pulmonary disease. Heart Lung. 2014;43(3):249-255.

48. Maltais F, Decramer M, Casaburi R, et al. An Official American Thoracic Society/European Respiratory Society Statement: update on limb muscle dysfunction in chronic obstructive pulmonary disease. Am J Respir Crit Care Med. 2014;189(9):e15-e62.

49. Handa R, Poanta L, Rusu D, Albu A. The role of heart rate variability in assessing the evolution of patients with chronic obstructive pulmonary disease. Rom J Intern Med. 2012;50(1):83-88.
International Journal of COPD

\section{Publish your work in this journal}

The International Journal of COPD is an international, peer-reviewed journal of therapeutics and pharmacology focusing on concise rapid reporting of clinical studies and reviews in COPD. Special focus is given to the pathophysiological processes underlying the disease, intervention programs, patient focused education, and self management protocols.

\section{Dovepress}

This journal is indexed on PubMed Central, MedLine and CAS. The manuscript management system is completely online and includes a very quick and fair peer-review system, which is all easy to use. Visit $\mathrm{http}: / / \mathrm{www}$. dovepress.com/testimonials.php to read real quotes from published authors. 